\title{
Chelating resin sorption followed by supercritical fluid extraction and liquid chromatographic determination of aluminum in liquid samples
}

\author{
Jian-Lian Chen ${ }^{\mathrm{a}}$, Chuen-Ying Liu ${ }^{\mathrm{b}, *}$ \\ a Department of Occupational Safety and Health, Chung Shan Medical University, 110 Section 1, \\ Chien-Kuo North Road, Taichung 402, Taiwan \\ ${ }^{\mathrm{b}}$ Department of Chemistry, National Taiwan University, Taipei, Taiwan
}

Received 4 April 2003; received in revised form 8 July 2003; accepted 5 August 2003

\begin{abstract}
To determine aluminum content in liquid samples, a method combining the techniques of chelating resin sorption and supercritical fluid extraction (SFE) was described. The chelating resin highly selective for aluminum at $\mathrm{pH}<3$ was prepared by impregnating Chromazural S (CAS) on Amberlite IRA-400. The sorbed aluminum was extracted with supercritical $\mathrm{CO}_{2}$ containing trifluoroacetylacetone (TFA). A $4^{5}$ factorial design was conducted for the simultaneous determination of various analytical SFE parameters including temperature, pressure, $\mathrm{CO}_{2}$ density, extraction time, and fluid flow rate. After removing excess TFA with $\mathrm{NaOH}(0.1 \mathrm{M})$, the extract was analyzed by HPLC with UV detection at $296 \mathrm{~nm}$. We also demonstrated that the interference from iron complex in the applied liquid sample was negligible in this procedure. The aluminum content in Oolong tea determined by our method, 1.46 and $1.10 \mathrm{ppm}$ in the first and second infusion, respectively, was successfully verified by spectrophotometry. The established method was also applied to determine the aluminum content in beer, Coca Cola, and orange juice. (C) 2003 Elsevier B.V. All rights reserved.
\end{abstract}

Keywords: Supercritical fluid extraction; Factorial design; Aluminum; Resin; Tea

\section{Introduction}

In 1965 [1], the first report that intracerebral inoculation of aluminum phosphate in rabbits resulted in the neurofibrillary tangles of Alzheimer's disease gave rise to the debate of the role of aluminum in Alzheimer's disease. Currently, many studies revealed that aluminum is no doubt a neurotoxicant linked to the neurocognitive dysfunction for both animals and humans [2]. Known sources of aluminum include air, antacids, antiperspirants, cosmetics, dental prepara-

\footnotetext{
* Corresponding author. Fax: +886-4-23248194.

E-mail address: cj1@ csmu.edu.tw (C.-Y. Liu).
}

tion, food additives, infant formulas, and parenteral nutrients, tea and water [3].

Atomic absorption spectrophotometry and atomic emission spectrometry are the two most commonly used techniques for the determination of aluminum [4,5]. However, even with their high sensitivity, the application of these two spectrometric methods is often limited due to the matrix interference, instrumental cost, and tedious maintenance. Chelation extraction is a convenient and efficient technique for pre-concentration and separation of metallic ions from solid and liquid samples. The metallochromic reagents, such as pyrocatechol violet (PCV), eriochrome cyanine R (ECR), Chromazural S (CAS), 
aluminon, oxine and morin, are aggressive to sequester $\mathrm{Al}$ from its organic complexes. Selective reaction of $\mathrm{Al}$ with these reagents was not only used to spectrophotometric or fluorimetric analysis, but also applied in the concentration occurring on sorbents, which had sorbed these reagents. Powell et al. had used the oxine-derivatised Fractogel and styrenedivinylbenzene polymer as pre-concentrators in FIA system [6,7]. They also calculated the fraction of $\mathrm{Al}$ bound by PVC, ECR as well as CAS in the presence of organic acids, and found among them CAS had the highest value [8]. CAS had been actually immobilized on a Nova-Pak $\mathrm{C}_{18}$ guard column [9] and Dowex anion-exchange resin [10] to act as concentration sorbents.

Recently, the metal complex solubilities in supercritical fluid (SF) and its application in metal extraction attract more and more attention. Compared with conventional solvent extraction, supercritical fluid extraction (SFE) is relatively fast, environment friendly, and its solvency characteristics can be adjusted with operating conditions. For the low polarity of supercritical $\mathrm{CO}_{2}$ solvent, the charge neutralization of the metallic ions requires chelating agents. $\beta$-Diketones and dithiocarbamates, especially fluorinated $\beta$-diketones, were among the popular choices. They are commercially available, well-studied in their coordination chemistry, and have been used in the SFE of transition metals [11-18], lanthanides [19,20], and actinides [21,22]. Some metallic ions, such as $\mathrm{Al}(\mathrm{III}), \mathrm{Be}(\mathrm{II})$, and $\mathrm{Cr}(\mathrm{III})$, which have coordination numbers equal to twice their oxidation state, exhibit coordinatively saturated neutral complexes without further forming in situ adduct and thereby relative stability in $\mathrm{SF} \mathrm{CO}_{2}$ medium.

A favorable partition trend much more toward the SF than the matrix indicates the high solubility in SF medium and also a great success of quantitative extraction in a reasonable time and thereby a minimum SF consuming. Most studies on SFE of metallic ions and metal chelates focused on relative inert matrices, such as sand or cellulose-based filter paper. There are only few reports on vigorous matrices such as organism, sediment, or sludge [18,23-25]. The SFE conditions have to be optimized so that the desired solutes possess SF affinity competitive to the matrix binding kinetically and also inhabit a thermodynamically stable state in the modified SF. Since many variables have to be considered simultaneously in SFE, factorial designs [26] and multilinear regression [27] both are formal optimization methods, excluding trial and error (univariate) procedure.

Here, we also present a factorial design for the SFE of synthetic resins, which are energetic derivative and capable of selective pre-concentration of aqueous aluminum samples, with an aid of fluorinated $\beta$-diketone ligand.

\section{Experimental}

\subsection{Chemicals and reagents}

Amberlite IRA-400 (Sigma, 16-50 mesh, 45\% humidity, 3.8 meq./g exchange capacity) was ion exchange resin $\left(\mathrm{Cl}^{-}\right.$form). Chromazural S (CAS, Merck, $f w=605.3$ ) and trifluoroacetylacetone (TFA, Lancaster, $1.281 \mathrm{~g} / \mathrm{ml}$ ) both were chelating reagents. $\mathrm{CO}_{2}$ supercritical fluid (Scott Speciality Gases, 99\% purity) and toluene (Alps, ultra pure grade) were solvents used. Methanol (TEDIA, HPLC/Spectro grade) was HPLC eluent. Aluminum chloride, sodium acetate, iron salt $\left(\mathrm{Fe}_{2}\left(\mathrm{SO}_{4}\right)_{3}\left(\mathrm{NH}_{4}\right)_{2} \mathrm{SO}_{4}\right)$, and petroleum benzine were the Merck chemicals for the synthesis of $\mathrm{Al}(\mathrm{TFA})_{3}$ and $\mathrm{Fe}(\mathrm{TFA})_{3}$.

\subsection{Apparatus}

A Suprex SFE system (Model: Prep Master EL) was equipped with a reciprocating dual pump (ultimate $500 \mathrm{~atm}$. supply), an oven (ultimate $150^{\circ} \mathrm{C}$ control), a six-port 2 position valve, a stainless steel vessel $(5 \mathrm{ml}$ capacity), and an automatic variable flow restrictor (stainless steel made, $10 \mathrm{~cm}$ length, $1 / 32$ in. i.d., $1 / 16$ in. o.d., $0.1-7.0 \mathrm{ml} / \mathrm{min}$ flow rate control, ultimate $100{ }^{\circ} \mathrm{C}$ control). To reduce the severe flux caused by mass expansion of the highly suppressed $\mathrm{CO}_{2}$ fluid, the drain part of the SFE system was modified with a deactivated fused silica capillary (Polymicro, $25 \mathrm{~cm} \times 50 \mu \mathrm{m}$ i.d., $375 \mu \mathrm{m}$ o.d.) as an extension to the steel restrictor. The capillary restrictor was wrapped in a heating tape to keep the fluid pressure at a moderate level release. The detailed construction is shown in Fig. 1.

The HPLC-UV system was assembly of injection valve (Rheodyne, Model 7125), sample loop (20 $\mu$ l), 


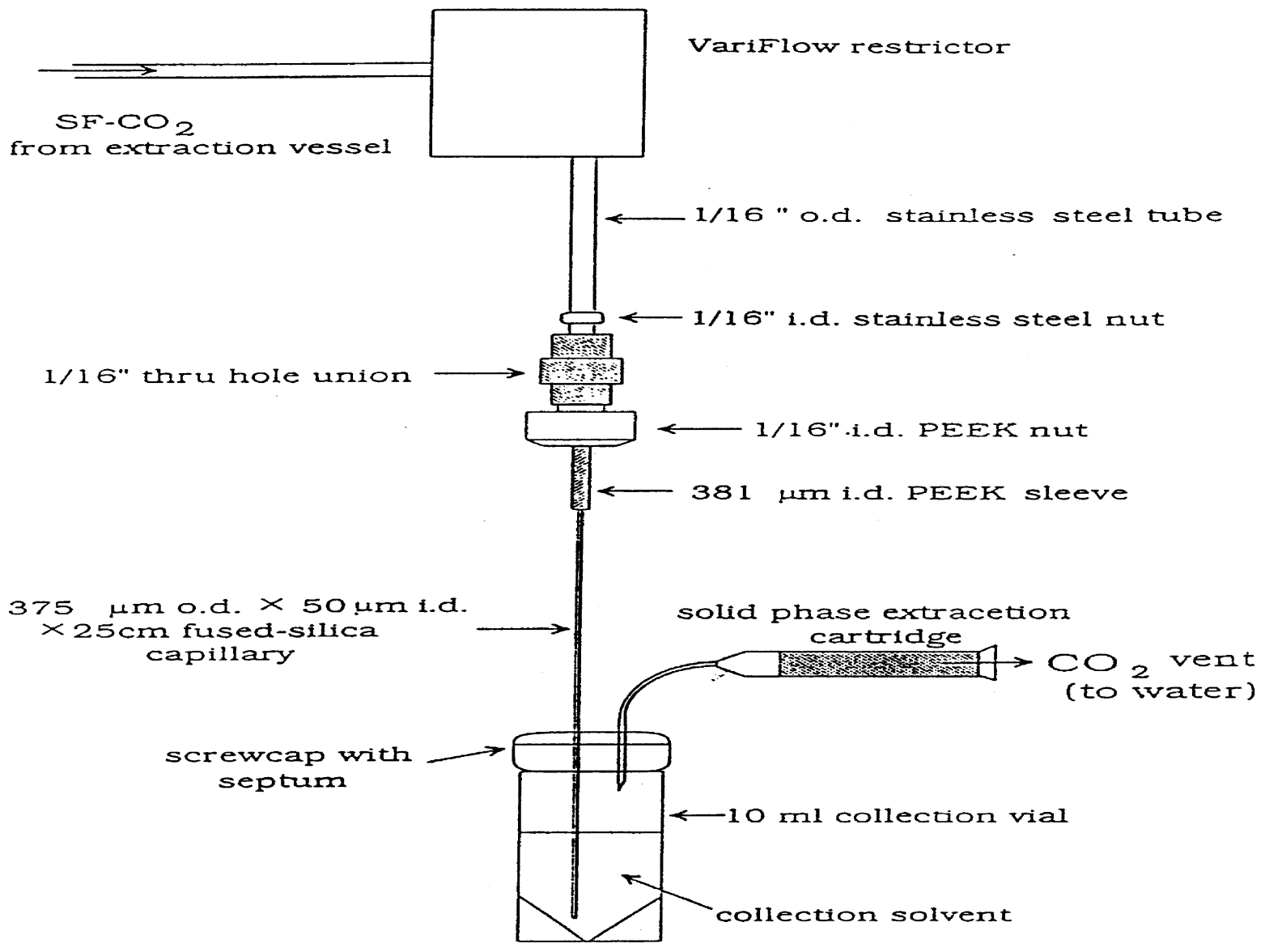

Fig. 1. Scheme of modified restrictor.

pump (Hitachi, Model L-6010), analytical column (Phase Sep, ODS2, $25 \mathrm{~cm} \times 4.6 \mathrm{~mm}$ i.d.), detector (Hitachi, Model L4200 UV-Vis Detector), and chromatogram integrator (Hitachi, Model D2500).

\subsection{Method}

\subsubsection{Preparation of IRA-CAS resin and its aluminum chelates}

The 140-230 meshed power ground from Amberlite IRA-400 resin was immersed in $\mathrm{NaCl}_{(\mathrm{aq})} 1 \mathrm{M}$ for 1 day. Filtered out $\mathrm{Cl}^{-}$ions by pouring a great quantity of water, the gel-like IRA-400 resin was dried to prepare IRA-CAS resin. This preparation was proceeding as mixing $75 \mathrm{ml}$ CAS aqueous solution $(0.1 \%$ $(\mathrm{w} / \mathrm{v}))$ with $15 \mathrm{~g}$ dried IRA-400 resin. After stirring, within 2 days the mixture was filtered and dried to get the target resin.

The IRA-CAS resin chelated with aluminum ion (IRA-CAS-Al) was obtained at an equilibrium of $2 \mathrm{~g} \mathrm{IRA}-\mathrm{CAS}$ resin, $1 \mathrm{ml} \mathrm{HCl}(\mathrm{aq})(2.5 \mathrm{M})$, and $25 \mathrm{ml}$ aluminum (1 ppm) for 7 days. For the following SFE evaluation, $0.2 \mathrm{~g}$ IRA-CAS-Al resin-spiked $15 \mu \mathrm{l}$ TFA (3000 times mole ratios) were taken as standard samples.

\subsubsection{Factorial design for the SFE condition and evaluation}

A four-level factorial design was employed to assess the significant five-factor (oven temperature that extraction vessel was supposed to be arrived at, $\mathrm{CO}_{2}$ pressure, static extraction time, dynamic elution time, 
Table 1

Design matrix for L16 $\left(4^{5}\right)$ factorial experiment and the resultant extraction efficiency

\begin{tabular}{lllllll}
\hline Experiment no. & A & B & C & D & E & $\begin{array}{l}\text { Recovery } \\
(\%)\end{array}$ \\
\hline 1 & 1 & 1 & 1 & 1 & 1 & 17.47 \\
2 & 1 & 2 & 2 & 2 & 2 & 14.17 \\
3 & 1 & 3 & 3 & 3 & 3 & 27.26 \\
4 & 1 & 4 & 4 & 4 & 4 & 10.86 \\
5 & 2 & 1 & 2 & 3 & 4 & 26.60 \\
6 & 2 & 2 & 1 & 4 & 3 & 7.62 \\
7 & 2 & 3 & 4 & 1 & 2 & 38.37 \\
8 & 2 & 4 & 3 & 2 & 1 & 37.33 \\
9 & 3 & 1 & 3 & 4 & 2 & 33.87 \\
10 & 3 & 2 & 4 & 3 & 1 & 36.88 \\
11 & 3 & 3 & 1 & 2 & 4 & 34.82 \\
12 & 3 & 4 & 2 & 1 & 3 & 42.80 \\
13 & 4 & 1 & 4 & 2 & 3 & 11.67 \\
14 & 4 & 2 & 3 & 1 & 4 & 41.44 \\
15 & 4 & 3 & 2 & 4 & 1 & 20.74 \\
16 & 4 & 4 & 1 & 3 & 2 & 25.07 \\
\hline
\end{tabular}

and the volume of methanol modifier added directly to the standard samples which were described above) for optimizing SFE condition. The L16 orthogonal array table (Tables 1 and 2) instructed the following 16 experiments in their individual parameters. For example, experiment no. 9 was assigned to the SFE parameters of $110^{\circ} \mathrm{C}$ oven temperature, $450 \mathrm{~atm} . \mathrm{CO}_{2}$ pressure, $10 \mathrm{~min}$ static time, $5 \mathrm{~min}$ dynamic time, and $0.5 \mathrm{ml}$ methanol spiked.

Irrespective of the working conditions, all samples were following the same procedure prior to SFE. In

Table 2

Factors and their average response values on L16 factorial design

\begin{tabular}{lllll}
\hline & 1 & 2 & 3 & 4 \\
\hline A & 50 & 80 & 110 & 140 \\
Oven temperature $\left({ }^{\circ} \mathrm{C}\right)$ & $(17.4)^{\mathrm{a}}$ & $(27.5)$ & $(37.1)$ & $(24.7)$ \\
$\mathrm{B}$ & 450 & 430 & 410 & 390 \\
$\mathrm{CO}_{2}$ pressure (atm) & $(22.4)$ & $(25.0)$ & $(30.3)$ & $(29.0)$ \\
$\mathrm{C}$ & 20 & 15 & 10 & 5 \\
Static time (min) & $(21.3)$ & $(26.1)$ & $(35.0)$ & $(24.5)$ \\
D & 20 & 15 & 10 & 5 \\
Dynamic time (min) & $(35.0)$ & $(24.5)$ & $(29.0)$ & $(18.3)$ \\
E & 75 & 50 & 25 & 0 \\
Methanol spiked (ml) & $(28.1)$ & $(27.9)$ & $(22.3)$ & $(28.4)$ \\
\hline
\end{tabular}

\footnotetext{
${ }^{a}$ Values in the parentheses are average response.
}

order to minimize potential interactions between the steel walls and chemicals in the samples, a piece of glass tubing $(5 \mathrm{~cm} \times 0.8 \mathrm{~cm}$ i.d. $)$ with sintered glass cap (100-150 mesh) at one opening was packed with sample, sealed with sufficient glass wool, and then placed in the extraction vessel. Finally, the extracted and eluted analytes were trapped in a collection vial. After refilling the collection solvent, toluene, to $1 \mathrm{ml}$, an additional $\mathrm{NaOH}_{(\mathrm{aq})}(1 \mathrm{ml}, 0.12 \mathrm{M})$ had been blended. Through shaking the mixture for $1 \mathrm{~min}$ and standing for $3 \mathrm{~min}$, the organic phase belonging to the upper layer was injected into the HPLC-UV system for quantitative evaluation.

\subsubsection{Treatment of samples}

One gram leaf had been infused with $100 \mathrm{ml}$ deionized water $\left(100^{\circ} \mathrm{C}\right)$ for $5 \mathrm{~min}$. The second infusion followed the same procedure. IRA-CAS resin of $0.5 \mathrm{~g}$ responded to the aluminum analysis of $25 \mathrm{ml}$ sample, whose $\mathrm{pH}$ was adjusted by the addition of $1 \mathrm{ml}$ $\mathrm{HCl}_{(\mathrm{aq})}(2.5 \mathrm{M})$. The chelated resin, whose formation was supposedly completed by selective sorption in 7 days, weighted $0.1 \mathrm{~g}$ ready for SFE and HPLC-UV analysis.

After $1 \mathrm{~g}$ leaf (or $100 \mathrm{ml}$ tea) had been digested by concentrated $\mathrm{HCl}$ (or $6 \mathrm{M} \mathrm{HCl}$ ) for $4 \mathrm{~h}$, the sample solution was obtained from the distillate and was ready for the spectroscopic analysis.

\subsubsection{Spectrophotometric analysis of aluminum}

The mixture of sample $(0.5 \mathrm{ml}$, aluminum weight less than $10 \mu \mathrm{g})$ and ascorbic acid $(1 \mathrm{ml}, 1 \%(\mathrm{w} / \mathrm{v}))$ was adjusted to $\mathrm{pH} 2$ by ammonia. After standing for $5 \mathrm{~min}$ and then adding water up to $15 \mathrm{ml}$, the mixture was blended with CAS $(2.5 \mathrm{ml}, 0.1 \%(\mathrm{w} / \mathrm{v}))$ and sodium acetate $(1 \mathrm{ml}, 20 \%(\mathrm{w} / \mathrm{v}))$. The final mixture was adjusted to $\mathrm{pH} 6$ by ammonia and adding water up to $25 \mathrm{ml}$. The absorbance peak was aimed at $545 \mathrm{~nm}$ with a blank background.

\section{Results and discussion}

The established method was achieved by calibrating the quantitative procedure and estimating the factorial experiments for SFE with a series of IRA-CAS-Al resin samples and eventually applied to the analysis of drinks. 
<smiles>CC1=CC(=C(c2cc(C)c(O)c(C(=O)O[Na])c2)c2c(Cl)ccc([SH]([O])(=O)O[Na])c2Cl)C=C(C(=O)O[Na])C1=O</smiles>

Fig. 2. CAS chemical structure.

\subsection{Preparation of IRA-CAS-Al samples}

The IRA-CAS resins were prepared by impregnating CAS $(75 \mathrm{mg}, 0.124 \mathrm{mmol})$ on the Amberlite IRA-400 anion exchangers ( $15 \mathrm{~g}, 57$ meq.). The CAS was assumed totally exchanged with anions in the strongly basic exchangers. Each CAS molecule, with structure shown in Fig. 2, bears three functional groups, including two carboxylic acids and one sulfonic acid. When IRA-CAS resin $(2 \mathrm{~g}, 16.5 \mu \mathrm{mol}$ CAS) was equilibrated with aluminum ions $(25 \mathrm{ml}$, $1 \mathrm{ppm}, 0.926 \mu \mathrm{mol})$ under acidic solution, there is only $45 \%$ absorption ratio measured by titrating the filtrate. Such ratio may be resulted from the steric hindrance and the high coordination numbers to neutralize the forming aluminum complexes, whose nearly forty CAS molecules chelated one aluminum ion. On the other hand, this result also indicated the difficulty of extracting the aluminum ions bounded in such constraint, although the TFA chelating agent added in SF is helpful.

\subsection{Calibration curve}

The extracts in the collection vial were expected to have excess of TFA ligand, as general 3000 times mole ratio of TFA to aluminum analyte was built in the extraction vessel. The simulated solution containing TFA and $\mathrm{Al}(\mathrm{TFA})_{3}$ tested the HPLC-UV system. The large quantity and strong UV $(296 \mathrm{~nm})$ absorption of TFA molecule responded to the chromatogram in Fig. 3a. A best solution [28] was to wash out the undesired peak by using $\mathrm{NaOH}_{(\mathrm{aq})}(0.12 \mathrm{M})$, allowing the analytical peak to appear (Fig. 3b). The retention time

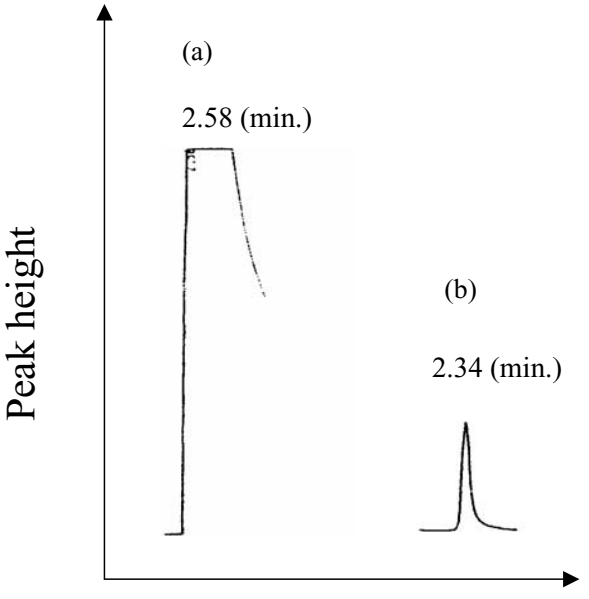

\section{Retention time}

Fig. 3. Determination of $\mathrm{Al}(\mathrm{TFA})_{3}$ in excess of TFA interference. Stationary phase: Spherisorb ODS $(250 \mathrm{~mm} \times 4.6 \mathrm{~mm}$ i.d. $)$; sample loop: $20 \mu \mathrm{l}$; eluent: methanol; detection: UV-Vis at $296 \mathrm{~nm}$. (a) Mixture of $\mathrm{Al}(\mathrm{TFA})_{3}(1 \mathrm{ppm})$ and TFA with molar ratio of 1:3000. (b) (a) treated with $\mathrm{NaOH}_{(\mathrm{aq})}$ (molar ratio of $\mathrm{NaOH}$ :TFA $=1: 1$ ).

and integrated area of the appearing peak was identical to peak of the pure $\mathrm{Al}(\mathrm{TFA})_{3}$ without $\mathrm{NaOH}_{(\mathrm{aq})}$ treatment. Even standing for $6 \mathrm{~h}$ after the washing, the organic portion in the solution still keep the original chromatographic characteristics.

The standard "wash" procedure as described in Section 2.3.3 was performed. A calibration curve with good linearity $\left(R^{2}=0.9998\right)$ under the $0.3-2.8 \mathrm{ppm}$ range of $\mathrm{Al}(\mathrm{TFA})_{3}$ in toluene solution was given. Although the well linearity implied the "wash" procedure generated well reproducibility, the large intercept was unusual and suspicious. The linear equation $y=77481 x+62059$ ( $y$ is the peak area, $x$ is the $\mathrm{Al}(\mathrm{TFA})_{3}$ concentration) and the experimental value both showed that $0.8 \mathrm{ppm} \mathrm{Al}(\mathrm{TFA})_{3}$ existed in the pure toluene solution. This also meant at least $0.8 \mathrm{ppm}$ aluminum in the toluene was capable of complexing with the extra large amount of TFA ligand. According to the most recent version of Merck Index, the highest grade of toluene still contains $0.5 \mathrm{ppm}$ aluminum. As a consequence, we could suppose that the equilibrium time during the mixing between TFA and collection solvent, toluene, should be taken into account in the establishment of standard procedure. 


\subsection{Factorial experiments}

Sixteen individual data and their average response to factors based on L16 factorial design are showed in Tables 1 and 2, respectively. The sequential order of obvious factors was A3, D1, C3, B3, and E4. As a result of that theoretical $(58.94 \%)$ and real $(36.69 \%)$ recovery were somewhat divergent, we tried replacing E4 with E1 and got the better recovery $(45.87 \%)$. We also tried to change the dynamic time, $20 \mathrm{~min}$ (D1) into $40 \mathrm{~min}(48.67 \% \mathrm{re}-$ covery) and $60 \mathrm{~min}$ (13.36\% recovery), but the loss of analyte in the collection vial became increasingly dominant as dynamic purging time increased. Considering the economic reason, we set the operational parameters, A3, D1, C3, B3, E1, as a standard SFE procedure.

We noticed that the temperature and pressure were both higher in our operational SFE system as compared with other works dealing with animated matrices [19,23-25]. A reasonable inference is that the higher pressure was responsible to keep the SF density and its solubility certain as the higher temperature was applied to overcome the barrier of mass transfer. Since the strong adsorption between aluminum and chelating resin had been well considered and resolved, our system may be used for the analysis of aluminum in solid sample.

\subsection{Analysis of drinks}

CAS is usually seen as an indicator or chelating reagent in titration analysis of metals. One of its special characteristics is the selective chelation with aluminum and iron under acidic condition $(\mathrm{pH}<3)$ $[10,29]$. The study [30] showed that the complexation dimmer form, $\mathrm{Al}_{2} \mathrm{H}_{-1} \mathrm{~L}_{2}$ (L: CAS), which exhibited a high stability constant $(\log \beta=12.92)$, predominated over other species in the solution at $\mathrm{pH}<3$. An attempt to neglect the interference from iron was achieved when the peak area of $\mathrm{Fe}(\mathrm{TFA})_{3}(100 \mathrm{ppm})$ was much smaller than that of $\mathrm{Al}(\mathrm{TFA})_{3}(1 \mathrm{ppm})$ by the HPLC-UV test.

Based on the following two assumptions, (1) aluminum species in the tea were all sorbed on the IRA-CAS resin, and (2) the extraction efficiency was both the same $(48.57 \%)$, the aluminum content was estimated to be 1.46 and $1.10 \mathrm{ppm}$ for first and second
Table 3

Aluminum content in drinks

\begin{tabular}{ll}
\hline Samples & Aluminum content $(\mathrm{ppm})$ \\
\hline Oolong tea & \\
$\quad$ First infusion & 1.459 \\
$\quad$ Second infusion & 1.100 \\
Taiwan beer & \\
$\quad$ Glass bottle & 0.523 \\
$\quad$ Aluminum can & 0.470 \\
Coca cola & \\
Glass bottle & 3.006 \\
$\quad$ Aluminum can & 2.685 \\
PE bottle & 1.959 \\
Orange juice & \\
$\quad$ Carton & 0.289 \\
Aluminum foil & 0.298 \\
Tap water & $1.241 \pm 0.046(n=5)$ \\
\hline
\end{tabular}

infusion, respectively. Although the estimated values fell in the range of $0.8-4.9 \mathrm{ppm}$ [31-35], the variation could be attributed to the sample preparation, such as the source of leaf and the infusion methods, and the consideration of limited sorption of aluminum species existing at $\mathrm{pH}<1$ solution.

Spectrophotometry is an accessible method to verify our build method. We established a calibration curve, which gave a linear equation $(y=0.0435 x+0.0821$; $y$ is the absorbance, $x$ is the aluminum concentration) with a good linearity $\left(R^{2}=0.9992\right)$ in the range of $0.2-5 \mathrm{ppm}$. The spectrograms of the standard solution, digested tea, and untreated tea are shown in Fig. 4. The aluminum concentration of the digested tea, whose spectrogram was almost identical to the standard, was determined as $1.426 \mu \mathrm{g} / \mathrm{ml}$ similar to the data $(1.46 \mathrm{ppm})$ mentioned in the above section. The data of both 478 and $330 \mu \mathrm{g} / \mathrm{g}$ were obtained from $1 \mathrm{~g}$ fresh leaf and its infused one, and they coincided well with the data of $100 \mathrm{ml}$ tea. The former data was very close to $476 \mu \mathrm{g} / \mathrm{g}$ reported in [31-33].

In addition, beverages were also tested, and their data are shown in Table 3. According to the estimation from the tap water sample, which showed $1.241 \pm$ $0.046(n=5)$, the limit of detection is nearly $0.1 \mathrm{ppm}$ $(\mathrm{S} / \mathrm{N}=3)$. Different packaging and/or factory production could explain how the difference between the same kinds of drinks came from. 

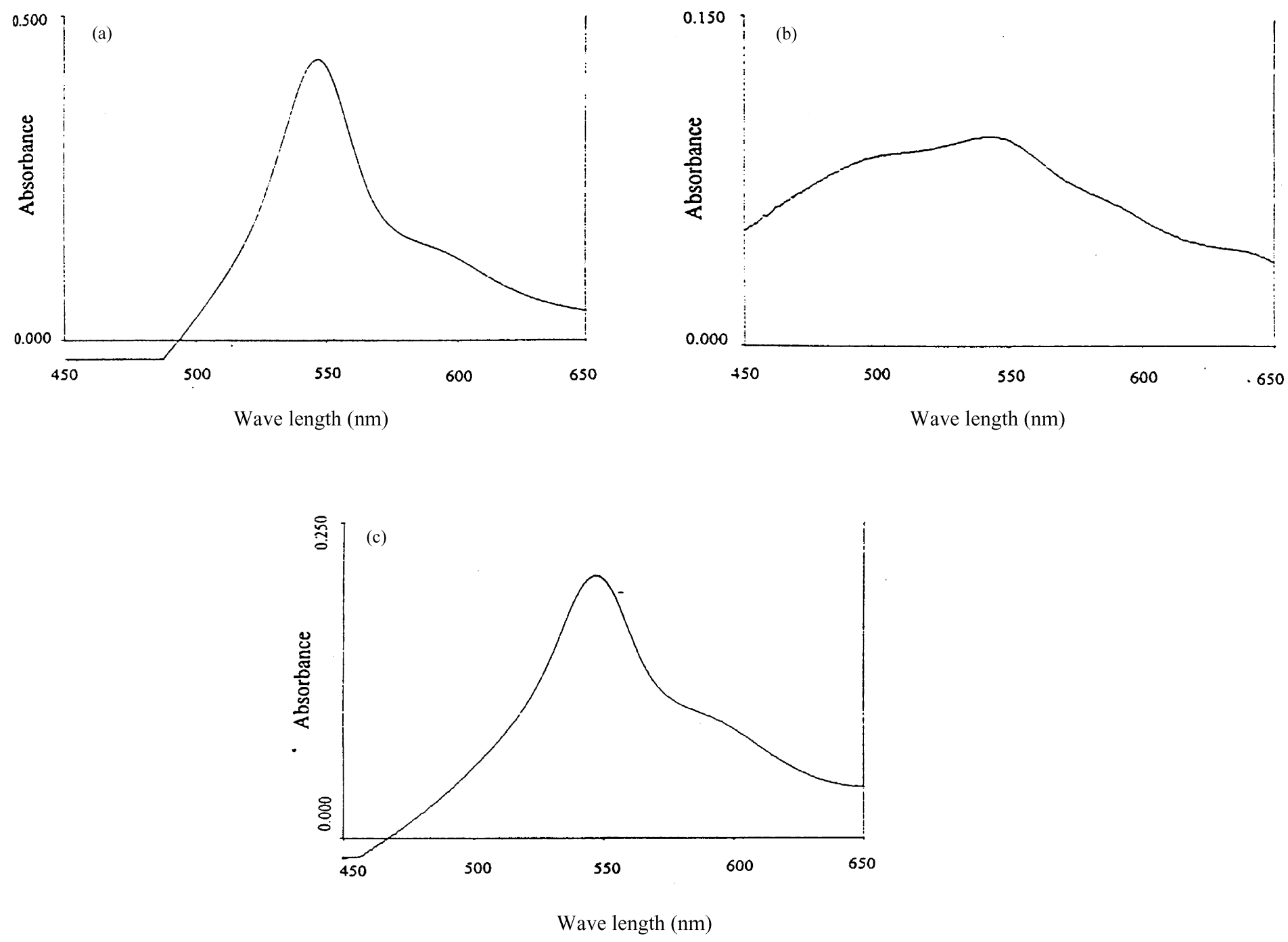

Fig. 4. The spectrograms of Al-CAS complex in different samples. (a) Aqueous standard; (b) original tea sample; (c) tea with acid digestion. Tea: infusion from 1.0 g oolong leaf by $100 \mathrm{ml} \mathrm{H}_{2} \mathrm{O}$ at $100^{\circ} \mathrm{C}$; acid digestion: digestion for $6 \mathrm{~h}$ by $6.0 \mathrm{M} \mathrm{HCl}$. 


\section{Conclusions}

In this study, we established an aluminum analysis system, which consisted of selectively chelating resin, optimized supercritical $\mathrm{CO}_{2}$ extraction, and HPLC-UV. Exclusion of the interference from other metals, L16 $\left(4^{5}\right)$ factorial design, and wash out of a matrix peak were also tested. These procedures were used to analyze the aluminum content in Oolong tea sample, and the results were verified by spectrophotometry, showing that the analysis with our method was successful. Our method had also been used to analyze aluminum in other drinks and showed potential in the application to solid samples.

\section{References}

[1] I. Klatzo, H. Wisniewski, J. Neutropathol. Exp. Neurol. 24 (1965) 187.

[2] T.P. Flaten, A.C. Alfrey, J.D. Birchall, J. Savory, R.A. Yokel, J. Toxicol. Environ. Health 48 (1996) 527.

[3] T.P. Flaten, Brain Res. Bull. 55 (2001) 187.

[4] M.A. Herrador, A.G. Gonzalez, Talanta 53 (2001) 1249.

[5] T.W. Lin, S.D. Huang, Anal. Chem. 73 (2001) 4319.

[6] S.L. Simpson, K.J. Powell, N.H.S. Nilsson, Anal. Chim. Acta 343 (1997) 19.

[7] K.J. Powell, Analyst 123 (1998) 797.

[8] D.J. Hawke, K.J. Powell, S.L. Simpson, Anal. Chim. Acta 319 (1996) 305.

[9] A.A. Almeida, X. Jun, L.F.C. Lima, Analyst 123 (1998) 1283.

[10] Z. Molodovan, L. Vlãdescu, Talanta 43 (1996) 1573.

[11] A.V. Yazdi, E.J. Beckman, Ind. Eng. Chem. Res. 35 (1996) 3644.

[12] M.Z. Ozel, M.D. Burford, A.A. Clifford, K.D. Bartle, A. Shadrin, N.G. Smart, N.D. Tinker, Anal. Chim. Acta 346 (1997) 73 .
[13] M.Z. Ozel, K.D. Bartle, A.A. Clifford, M.D. Burford, Anal. Chim. Acta 417 (2000) 177.

[14] J. Murphy, C. Erkey, Ind. Eng. Chem. Res. 36 (1997) 5371.

[15] J. Murphy, C. Erkey, Environ. Sci. Technol. 31 (1997) 1674.

[16] K.E. Laintz, C.D. Hale, P. Stark, C.L. Rouquette, J. Wilkinson, Anal. Chem. 70 (1998) 400.

[17] C.M. Wai, S. Wang, Y. Liu, V. Lopez-Avila, W.F. Beckert, Talanta 43 (1996) 2083.

[18] S. Wang, C.M. Wai, Environ. Sci. Technol. 30 (1996) 3111.

[19] O. Tomioka, Y. Enokida, I. Yamamoto, T. Takahashi, Prog. Nucl. Energy 37 (2000) 417-422.

[20] Y. Lin, H. Wu, N.G. Smart, C.M. Wai, Sep. Sci. Technol. 36 (2001) 1149-1162.

[21] Y. Lin, C.M. Wai, F.M. Jean, R.D. Brauer, Environ. Sci. Technol. 28 (1994) 1190.

[22] A.A. Murzin, V.A. Babain, A.Yu. Shadrin, I.V. Smirnov, A.A. Lumpov, N.I. Gorshkov, A.E. Miroslavov, M.Z. Muradymov, Radiochemistry 43 (2001) 177.

[23] J. Wang, W.D. Marshall, Anal. Chem. 66 (1994) 3900.

[24] M. Ashraf-Khorassani, L.T. Taylor, Anal. Chim. Acta 379 (1999) 1.

[25] S.M. Loyland, M. Yeh, C. Phelps, S.B. Clark, J. Radioanal. Nucl. Chem. 248 (2001) 493.

[26] F. Reche, M.C. Garrigos, A. Sanchez, A. Jimenez, J. Chromatogr. A 896 (2000) 51.

[27] M. Careri, L. Furlattini, A. Mangia, M. Musci, E. Anklam, A. Theobald, C. von Holst, J. Chromatogr. A 912 (2001) 61.

[28] T.A. Gosink, Anal. Chem. 47 (1975) 165.

[29] K. Ueno, T. Imamura, K.L. Cheng, Handbook of Organic Analytical Reagents, CRC Press, Boca Raton, FL, 1992, p. 67.

[30] D.J. Hawke, K.J. Powell, Polyhedron 14 (1995) 377.

[31] J.Y. Liang, T.H. Shyu, H.C. Lin, J. Chin. Agric. Chem. Sci. 34 (1996) 695.

[32] J.Y. Liang, C.H. Yen, C.H. Lin, J. Chin. Agric. Chem. Sci. 35 (1997) 61.

[33] K. Odegard, W. Lund, J. Anal. Atom. Spectrom. 12 (1997) 403.

[34] M.H. Wong, Z.Q. Zhang, J.W.C. Wong, C.Y. Lan, Environ. Geochem. Health 20 (1998) 87.

[35] T. Miyahara, H. Kitamura, K. Narita, T. Toyo'oka, Biomed. Chromatogr. 13 (1999) 70. 